\title{
ROLE OF SURGICAL TURBINOPLASTY IN THE MANAGEMENT OF INFERIOR TURBINATE HYPERTROPHY: A CASE SERIES
}

Sabarinath Vijayakumar'1, Shilpa Divakaran²

\section{HOW TO CITE THIS ARTICLE:}

Sabarinath Vijayakumar, Shilpa Divakaran. "Role of Surgical Turbinoplasty in the Management of Inferior Turbinate Hypertrophy: A Case Series". Journal of Evolution of Medical and Dental Sciences 2015; Vol. 4, Issue 21, March 12; Page: 3655-3661, DOI: $10.14260 /$ jemds/2015/526

ABSTRACT: OBJECTIVES: To evaluate the efficacy of surgical turbinoplasty in alleviating the symptoms of allergic inferior turbinate hypertrophy. MATERIALS AND METHODS: This prospective study was conducted on 30 adult patients with symptomatic hypertrophy of inferior turbinate which was refractory to medical treatment. All patients underwent surgical turbinoplasty. Symptoms were assessed using SNOT score pre-operatively and at 1 week, 1 and 3 months postoperatively. RESULTS: All 30 patients showed significant improvement in symptoms right from the first post-operative week, which persisted till the last follow-up at 3 months. There was a significant decrease in the SNOT scores for nasal obstruction, headache, sneezing, nasal discharge and pain at 1 week, 1 and 3 months ( $<$ 0.05). Overall, there was improvement in the symptoms of nasal obstruction, nasal discharge, sneezing, headache and pain in $90 \%, 85.71 \%, 75 \%, 80 \%$ and $90 \%$ of patients, respectively. CONCLUSION: Surgical turbinoplasty is a safe and effective modality in the treatment of allergic inferior turbinate hypertrophy.

KEYWORDS: Inferior turbinate hypertrophy, Surgical turbinoplasty.

INTRODUCTION: Nasal obstruction is a common complaint encountered in the daily practice of Otorhinolaryngology. It can range from a minor disturbance to significant discomfort affecting the quality of life. Inferior turbinate hypertrophy may be seen in cases like allergic perennial rhinitis, vasomotor rhinitis, and chronic hypertrophic rhinitis or as a compensatory response to a septal deformity.[1] So a patient with inferior turbinate hypertrophy can present with symptoms like sneezing, rhinorrhea and headache in addition to nasal obstruction.

Over the years, various surgical procedures like turbinectomy, turbinoplasty, radiofrequency volumetric tissue reduction and laser assisted turbinoplasty have been advocated for hypertrophy of the inferior turbinate, with the goal of increasing the nasal patency and preserving the mucosa. ${ }^{[2,3]}$ This prospective study was undertaken to evaluate the efficacy of surgical turbinoplasty in the treatment of ITH secondary to allergic rhinitis in South Indian population.

MATERIALS AND METHODS: The study was a prospective study. The study protocol was reviewed and approved by the Department of ENT and by the Ethical Committee of Sri Manakula Vinayagar Medical College and Hospital.

The treatment procedure was explained to all the patients and written consent was taken in both English and Tamil. The patients were given full freedom to clear their doubts about the procedure and their participation in the study.

All adult patients attending the ENT Outpatient department of Sri Manakula Vinayagar Medical College and Hospital, Pondicherry from May 2014 to December 2014 with inferior 
turbinate hypertrophy due to allergic rhinitis refractory to medical treatment were included in the study.

Patients with bleeding diathesis, acute respiratory tract infections, previous nasal surgeries or trauma, gross deviation of nasal septum, associated sinonasal disease, malignancy of nose and paranasal sinuses and co-morbidities like uncontrolled diabetes mellitus and hypertension were excluded from the study.

History of persistent nasal obstruction, nasal discharge, along with other symptoms of allergic rhinitis were noted. All patients received medical treatment in the form of topical nasal decongestants, antihistamines and topical steroid nasal spray for at least 12 weeks. Patients who had persistent symptoms after 12 weeks were considered as refractory to medical treatment.

All patients underwent a general examination and a detailed otorhinolaryngological examination. Diagnostic nasal endoscopy was done for evaluation of hypertrophied turbinate and to exclude other pathology using "Karl Storz Endoskope" $\left(0^{0}\right.$ and $\left.30^{\circ}\right)$. Absolute eosinophil count and serum IgE levels were done for all patients and patients with peripheral eosinophilia and elevated serum IgE levels were included in the study.

The symptoms of nasal obstruction, headache, sneezing, nasal discharge and pain were assessed on the basis of SNOT scoring system. SNOT (Sino nasal outcome test) scoring system:

0 - no problem

1 - Very mild problem

2 - Mild or slight problem

3 - Moderate problem

4 - Severe problem

5 - Problem as bad as it can be

Surgical Turbinoplasty Procedure: Under endoscopic guidance using 0 degree scope, inferior turbinate was infractured medially with a Freer elevator. A no. 15 blade was used to make an incision through mucosa and stroma, down to conchal bone, extending from the turbinate attachment downwards across the anterior tip and along the inferior edge of the turbinate.

An elevator was then employed to elevate soft tissue and mucosa off the medial surface of the conchal bone, at this time the incision was extended posteriorly to the posterior limit of the conchal bone. A curved haemostat was then inserted and the conchal bone crushed. Turbinectomy scissors were used to completely resect the conchal bone from its attachment to the lateral nasal valve, out lining an elongated inferior - lateral wedge of bone, turbinate stroma and mucosa.

The resultant flap was rolled upon itself from medial to lateral, to form the neoturbinate with two opposing surfaces and external mucosal lined surface. Endoscopy also ensured that all bleeding points were visualised and bleeding controlled, all mucosal tags were also removed. The nasal cavity was then packed with ribbon gauze soaked in acriflavin and liquid paraffin, which was removed after 48 hours.

Post operatively analgesics were routinely given for 2-3 days, anti histaminics for 4 days and topical nasal decongestant drops given for 4-5 days. Antibiotics were not prescribed and were reserved for postoperative complications like infection, bleeding, etc.

Follow up was done at 1 week, 1 month and 3 months post-surgery. At each follow up visit symptoms were assessed by SNOT scoring system. 
STATISTICAL ANALYSIS: All the data were analysed using SPSS 19 (Statistical Package for the Social sciences: SPSS version 19.0, for Windows, Chicago, IL) statistical software. Wilcoxon matched - paired test and paired t test was employed to analyze the difference between pre-operative and post-operative SNOT score. For all the tests, $\mathrm{p}$ value of less than 0.05 was taken as significant.

OBSERVATION AND ANALYSIS: All 30 patients completed the study. There were 14 male and 16 female patients. The most common age group was 18-33 yrs (46.7\%), with the mean age being 35.7 yrs. Pre-operative symptoms along with average SNOT scores are depicted in Table 1.

\begin{tabular}{|c|c|c|}
\hline Symptoms & No. Of patients having symptoms (\%) & Average SNOT score \\
\hline Nasal obstruction & $30(100)$ & 2.93 \\
\hline Nasal discharge & $28(93.3)$ & 1.80 \\
\hline Sneezing & $28(93.3)$ & 1.97 \\
\hline Headache & $20(66.7)$ & 1.53 \\
\hline Pain & $10(33.3)$ & 0.53 \\
\hline \multicolumn{2}{|c|}{ Table 1: Pre-operative symptoms and average SNOT scores } \\
\hline
\end{tabular}

All patients in the study had bilateral inferior turbinate hypertrophy with normal osteomeatal complex. The mean duration of surgery was 16.03 min (SD 1.4).

\section{COMPLICATIONS:}

Intra operative complications: There were only minimal intra operative complications. $26.6 \%$ of the patients did not have any significant intra operative complications. The main complication which was noted intra operatively was burning sensation in the nose (36.7\%). Other complications were pain (20\%), bleeding (16.7\%).

Complications in the immediate post-operative period: In the immediate post-operative period the main complication which was seen in all patients was nasal crusting. Oedema of the turbinate mucosa was seen in $23.33 \%$ of the patients which disappeared within 2-3 days. Other complications were pain (33.33\%), blood stained nasal discharge (20.68\%). In all cases the bleeding was controlled by decongestant drops. None of the patients required any nasal packing or blood transfusion.

Out of the 30 patients who underwent Surgical turbinoplasty $26.7 \% \%$ did not have any intra-operative complications. The remaining patients had minor complications as shown in Table 2 .

\begin{tabular}{|c|c|c|c|c|}
\hline Complication & $\begin{array}{c}\text { Immediate post op } \\
\text { Number (\%) }\end{array}$ & $\begin{array}{c}\text { 1 week } \\
\text { Number (\%) }\end{array}$ & $\begin{array}{c}\text { 1 month } \\
\text { Number (\%) }\end{array}$ & $\begin{array}{c}\text { 3 months } \\
\text { Number (\%) }\end{array}$ \\
\hline Bloody nasal discharge & $6(20 \%)$ & $4(13.33 \%)$ & $7(23.33 \%)$ & Nil \\
\hline Pain & $10(33.3 \%)$ & $3(10 \%)$ & Nil & Nil \\
\hline Crusting & $30(100 \%)$ & $12(40 \%)$ & $3(10 \%)$ & Nil \\
\hline Mucosal edema & $7(23.33 \%)$ & Nil & Nil & Nil \\
\hline
\end{tabular}


ORIGINAL ARTICLE

\begin{tabular}{|c|c|c|c|c|}
\hline Burning sensation & Nil & Nil & Nil & Nil \\
\hline Synechiae & Nil & Nil & Nil & Nil \\
\hline
\end{tabular}

All patients showed significant improvement in symptoms post-operatively with improved SNOT scores at each follow-up visit, as shown in Table 3. The number of patients who experienced symptom relief is shown in Table 4.

\begin{tabular}{|c|c|c|c|c|c|c|}
\hline \multirow{2}{*}{ SYMPTOMS } & \multirow{2}{*}{ GROUP } & \multicolumn{3}{|c|}{ PAIRED DIFFERENCES } & \multirow{2}{*}{$\begin{array}{c}\text { P } \\
\text { VALUE }\end{array}$} & \multirow{2}{*}{$\begin{array}{l}\text { SIGNIFICANT } \\
\text { DIFFERENCE }\end{array}$} \\
\hline & & MEAN & SD & SEM & & \\
\hline \multirow{3}{*}{$\begin{array}{c}\text { Nasal } \\
\text { obstruction }\end{array}$} & Pre op and 1 week follow up & 0.5000 & 0.5085 & 0.0928 & $<0.0001$ & Yes \\
\hline & $\begin{array}{c}\text { Pre op and } 1 \text { month follow } \\
\text { up }\end{array}$ & 1.733 & 0.9803 & 0.1790 & $<0.0001$ & Yes \\
\hline & $\begin{array}{c}\text { Pre op and } 3 \text { months follow } \\
\text { up }\end{array}$ & 2.433 & 0.9714 & 0.1774 & $<0.0001$ & Yes \\
\hline \multirow{3}{*}{$\begin{array}{c}\text { Nasal } \\
\text { discharge }\end{array}$} & Pre op and 1 week follow up & 0.9667 & 0.6687 & 0.1221 & $<0.0001$ & Yes \\
\hline & $\begin{array}{c}\text { Pre op and } 1 \text { month follow } \\
\text { up }\end{array}$ & 1.433 & 0.7739 & 0.1431 & $<0.0001$ & Yes \\
\hline & $\begin{array}{c}\text { Pre op and } 3 \text { months follow } \\
\text { up }\end{array}$ & 1.667 & 0.8841 & 0.1614 & $<0.0001$ & Yes \\
\hline \multirow{3}{*}{ Sneezing } & Pre op and 1 week follow up & 0.9000 & 0.5472 & 0.1000 & $<0.0001$ & Yes \\
\hline & $\begin{array}{c}\text { Pre op and } 1 \text { month follow } \\
\text { up }\end{array}$ & 1.467 & 0.7303 & 0.1333 & $<0.0001$ & Yes \\
\hline & $\begin{array}{c}\text { Pre op and } 3 \text { months follow } \\
\text { up }\end{array}$ & 1.733 & 0.7849 & 0.1433 & $<0.0001$ & Yes \\
\hline \multirow{3}{*}{ Headache } & Pre op and 1 week follow up & 0.7667 & 0.8976 & 0.1639 & $<0.0001$ & Yes \\
\hline & $\begin{array}{c}\text { Pre op and } 1 \text { month follow } \\
\text { up }\end{array}$ & 1.167 & 1.117 & 0.2039 & $<0.0001$ & Yes \\
\hline & $\begin{array}{c}\text { Pre op and } 3 \text { months follow } \\
\text { up }\end{array}$ & 1.400 & 1.276 & 0.2329 & $<0.0001$ & Yes \\
\hline \multirow{3}{*}{ Pain } & Pre op and 1 week follow up & 0.2333 & 0.4302 & 0.0785 & 0.0059 & Yes \\
\hline & $\begin{array}{c}\text { Pre op and } 1 \text { month follow } \\
\text { up }\end{array}$ & 0.4667 & 0.7303 & 0.1333 & 0.0015 & Yes \\
\hline & $\begin{array}{c}\text { Pre op and } 3 \text { months follow } \\
\text { up }\end{array}$ & 0.5000 & 0.7768 & 0.1418 & 0.0014 & Yes \\
\hline
\end{tabular}

Table 3: Statistical analysis of SNOT scores after surgical turbinoplasty

SYMPTOMS

No. of patients having
symptoms preoperatively

No. of patients who Obtained symptom relief (\%)

J of Evolution of Med and Dent Sci/ eISSN- 2278-4802, pISSN- 2278-4748/ Vol. 4/ Issue 21/ Mar 12, 2015 Page 3658 


\begin{tabular}{|c|c|c|}
\hline Nasal obstruction & 30 & $27(90 \%)$ \\
\hline Nasal discharge & 28 & $24(85.71 \%)$ \\
\hline Sneezing & 28 & $21(75 \%)$ \\
\hline Headache & 20 & $16(80 \%)$ \\
\hline Pain & 10 & $9(90 \%)$ \\
\hline \multicolumn{2}{|r|}{ Table 4: Symptom relief at 3rd post-operative month } \\
\hline
\end{tabular}

DISCUSSION: Surgical manipulation of the inferior turbinates has been a widely used procedure for more than 100 years to improve the nasal airway. Various techniques are currently performed to reduce the volume of the mucosal and sometimes bony tissues of the inferior turbinates. Most of these techniques provide satisfactory results for a more or less long period. But no technique is perfect and each is associated with known short term and long term complications. An ideal procedure would be one that provides maximum symptom relief with minimum morbidity. The aim of this study is to calculate the symptomatic relief in patients with allergic rhinitis following surgical turbinoplasty.

The symptomatic assessment was done based on SNOT scoring (Sino Nasal Outcome Test) in which 0 is No Problem and 5 is Problem as bad it can be. The SNOT covers a broad range of health and health-related quality of life problems including "physical problems, functional limitations, and emotional consequences. ${ }^{[4]}$ The SNOT summary score may range from 0 to 100 or 0 to 5 depending on the scoring method used.[5] Yaniv E et al used SNOT 16 scoring system in assessing the effect of KTP laser turbinate reduction on inferior turbinate hypertrophy. In this study the change in the symptom score post operatively was noted.[6]

NASAL OBSTRUCTION: There was significant improvement in nasal obstruction. However, owing to post- operative odema, there was an initial worsening of obstruction, which improved by first week. This difference was found to be statistically significant. The improvement in nasal obstruction persisted throughout the follow up period ( $p$ value $<0.0001$ ). Schmelzer et al reported relief in nasal obstruction by $93.5 \%$ in patients undergoing surgical turbinoplasty.[7] Other studies like Katz et al reported an improvement in $94.7 \%$ of the patients.[8]

In our study at the end of 3 months 3 patients out of 30 patients gave history of residual nasal obstruction, but they were very mild or mild problem according to SNOT scoring system.

Nasal discharge: Initially $93.3 \%$ of patients complained of excessive nasal discharge. At the end of the 3 month follow up, $85.71 \%$ of the patients had obtained significant relief in nasal discharge (p value $<0.0001$ ). In a study by Cavaliere $M$ et al there was significant reduction in the nasal discharge VAS after 1 and 3 months in both RFVTR and surgical turbinoplasty group.[9] Similar observations were made in other studies. ${ }^{[10,11]}$

Sneezing: In the preoperative evaluation, $93.3 \%$ of the patients had sneezing. At the end of the 3 month follow up period it was found that $75 \%$ of the patients had obtained significant relief in sneezing ( $p$ value $<0.0001$ ). The reason for relief of sneezing and nasal discharge may be attributed to destruction of the branches of post nasal nerve. In the study by Cavaliere $\mathrm{M}$ et al there was significant reduction in the sneezing VAS after 1 and 3 months.[9] 
Headache: At the end of the 3 month follow up period $80 \%$ of the patients showed an improvement in headache. There was a significant decrease in the SNOT scores at 1 week, 1 month and 3 months ( $p$ value $<0.0001$ ). In a study by Matteo $C$ et al there was significant reduction in the headache after 1 and 3 months in both Radiofrequency associated turbinate reduction and surgical turbinoplasty group.[9] The degree of improvement in the RFVTR group was $62 \%$ at the end of first month and $69 \%$ at the end of 3 months.

Pain: $33.3 \%$ of patients in our study complained of nasal pain which is not a common complaint in allergic rhinitis. As the proportion of patients who had this symptom was significant, this symptom was included in the study. We found that pain was significantly reduced at each follow up visit 1 week ( $p$ value $<0.0059$ ), 1 month ( $p$ value $<0.0015$ ) and 3 months ( $p$ value $<0.0014$ ). At the end of 3 months, $90 \%$ of patients were relieved of the symptom.

\section{POST OP COMPLICATIONS:}

Crusting: Crusting was seen in $40 \%$ of the patients at the end of 1 week follow up. At the end of 1 month only 3 patients (10\%) and at 3 months, none had crusting.

Our study implies that the time taken for the crusts to disappear is $1-3$ months after surgical turbinoplasty.

Pain: Pain was one of our preoperative symptoms considered, so post-operative scoring using SNOT was done for pain. Three patients, who did not have pain as an initial symptom, complained of pain at the end of 1 week post-surgery. All three patients did not have pain in the subsequent follow up visits.

Bleeding/Blood stained nasal discharge: Blood stained nasal discharge was encountered in $3(10 \%)$ patients. In all the cases the bleeding was controlled with topical decongestant drops. These patients never complained of blood stained discharge in the subsequent visits.

All these post-operative complications were minor and of short duration as was observed by Putermann et al in his study.[10]

CONCLUSION: Surgical turbinoplasty plays a significant role in relieving symptoms in patients with inferior turbinate hypertrophy refractory to medical treatment. Surgical turbinoplasty is a safe, effective, minimally invasive procedure, well tolerated by the patients and can be performed on a day care basis. Longer follow up is required to assess the development of late complications and recurrence of symptoms after surgical turbinoplasty.

\section{REFERENCES:}

1. Passàli D, Passàli FM, Damiani V, Passàli GC, Bellussi L. Treatment of inferior turbinate hypertrophy: a randomized clinical trial. Ann Otol Rhinol Laryngol. 2003; 112(8): 683-8.

2. Brunworth J, Holmes J, Sindhwani R. Inferior turbinate hypertrophy: Review and graduated approach to surgical management. Am J Rhinol Allergy. 2013 Sep-Oct; 27(5): 411-5.

3. Elwany S, Harrison R. Inferior turbinectomy: comparison of four techniques. J Laryngol Otol. 1990; 104(3): 206-9. 


\section{ORIGINAL ARTICLE}

4. Piccirillo JF, Merritt MG, Richards ML. Psychometric and clinimetric validity of the 20-item Sino-Nasal Outcome Test (SNOT-20). Otolaryngol Head Neck Surg 2002; 126: 41-7.

5. Browne JP, Hopkins C, Slack R, Cano SJ. The Sino-Nasal Outcome Test (SNOT): can we make it more clinically meaningful? Otolaryngol Head Neck Surg 2007; 136: 736-41.

6. Yaniv E, M.D., Hadar T, M.D KTP/532 YAG laser treatment for allergic rhinitis: Am J Rhinol Allergy 23, 2009: 527-530.

7. Schmelzer B et al. Long-term efficacy of our surgical approach to turbinate hypertrophy. Am J Rhinol. 1999 Sep-Oct; 13(5): 357-61.

8. Katz $\mathrm{S}$ et al. Our technique of partial inferior turbinoplasty: long-term results evaluated by rhinomanometry. Acta Otorhinolaryngol Belg. 1996; 50(1): 13-8.

9. Cavaliere M, Mottola G, Iemma M. Comparison of the effectiveness and safety of radiofrequency turbinoplasty and traditional surgical technique in treatment of inferior turbinate hypertrophy. Otolaryngol Head Neck Surg 2005; 133: 972-8.

10. Puterman MM, Segal N, Joshua BZ. Endoscopic, assisted, modified turbinoplasty with mucosal flap. J Laryngol Otol 2012 May; 126(5): 525-8.

11. Elwany S, Harrison R. Inferior turbinectomy: comparison of four techniques. J Laryngol Otol. 1990; 104(3): 206-9.

\section{AUTHORS:}

1. Sabarinath Vijayakumar

2. Shilpa Divakaran

\section{PARTICULARS OF CONTRIBUTORS:}

1. Assistant Professor, Department of ENT, Sri Manakula Vinayagar Medical College \& Hospital.

2. Assistant Professor, Department of ENT, Pondicherry Institute of Medical Sciences.

FINANCIAL OR OTHER

COMPETING INTERESTS: None

\section{NAME ADDRESS EMAIL ID OF THE} CORRESPONDING AUTHOR:

Dr. Sabarinath Vijayakumar,

No. 1, Narmadha Street,

Vasanth Nagar, Muthialpet,

Pondicherry-605003.

E-mail: drsabarinathv@gmail.com

Date of Submission: 05/02/2015.

Date of Peer Review: 06/02/2015.

Date of Acceptance: 28/02/2015.

Date of Publishing: 11/03/2015. 